\title{
Retinal Vascular Changes in Patients with Chronic Obstructive Pulmonary Disease: An Optical Coherence Tomography Angiography Study
}

\author{
(1) Abdurrahman Alpaslan Alkan, ${ }^{1}$ (i) Eyup Duzgun, ${ }^{2}$ (i) Murat Karapapak, ${ }^{2}$ (i) Mufide Arzu Ozkarafakili, ${ }^{3}$ \\ (1) Ece Ozdemir Zeydanli, ${ }^{4}$ (D) Gurcan Dogukan Arslan, ${ }^{5}$ (D) Mehmet Egemen Karatas, ${ }^{2}$ (I) Dilek Guven ${ }^{2}$ \\ 'Department of Ophthalmology, Ercis Sehit Ridvan Cevik State Hospital, Van, Turkey \\ ${ }^{2}$ Department of Ophthalmology, University of Health Sciences Turkey, Sisli Hamidiye Etfal Training and Research Hospital, \\ Istanbul, Turkey \\ ${ }^{3}$ Department of Thoracic Diseases, University of Health Sciences Turkey, Sisli Hamidiye Etfal Training and Research Hospital, \\ Istanbul, Turkey \\ ${ }^{4}$ Department of Ophthalmology, Ardahan State Hospital, Ardahan, Turkey \\ ${ }^{5}$ Department of Ophthalmology, Tatvan State Hospital, Bitlis, Turkey
}

\begin{abstract}
Objectives: In the current study, we aimed to investigate retinal vascular density and blood flow changes in patients with chronic obstructive pulmonary disease (COPD) using optical coherence tomography angiography (OCTA) (AngioVue Avanti, Optovue). Methods: Thirty eyes of 30 patients with COPD and 30 eyes of 30 healthy controls were evaluated with OCTA. Foveal and parafoveal vessel density, inner retinal and choriocapillary flow area, and foveal avascular zone (FAZ) area were measured and compared between the groups.

Results: No statistically significant differences were observed in the outer retinal flow area and choriocapillary flow area measurements between the groups ( $p=0.609$ and $p=0.162$, respectively). There was no statistically significant difference in FAZ and FAZ perimeter values between the groups ( $p=0.725$ and $p=0.820$, respectively). Vascular density measurements in the superficial foveal and parafoveal areas were not statistically significantly different between the groups ( $p>0.05$, for all). Deep parafoveal vascular density values of the COPD group were statistically significantly lower than the control group in all investigated areas except the superior and inferior quadrants.

Conclusion: The results of our study demonstrated for the first time that vascular density decreased in the parafoveal area due to COPD-related hypoxemia and endothelial dysfunction.

Keywords: Chronic obstructive pulmonary disease, deep capillary plexus, foveal avascular zone, optical coherence tomography angiography, superficial capillary plexus.

Please cite this article as "Alkan AA, Duzgun E, Karapapak M, Ozkarafakili MA, Ozdemir Zeydanli E, Arslan GD, et al. Retinal Vascular Changes in Patients with Chronic Obstructive Pulmonary Disease: An Optical Coherence Tomography Angiography Study. Med Bull Sisli Etfal Hosp 2021;55(2):210-216".
\end{abstract}

\footnotetext{
Address for correspondence: Abdurrahman Alpaslan Alkan, MD. Ercis Sehit Ridvan Cevik Devlet Hastanesi, Goz Hastaliklari Klinigi, Van, Turkey
} Phone: +90 5419383838 E-mail: alpaslanalkan06@gmail.com

Submitted Date: July 08, 2020 Accepted Date: September 03, 2020 Available Online Date: July 04,2021

${ }^{\circ}$ Copyright 2021 by The Medical Bulletin of Sisli Etfal Hospital - Available online at www.sislietfaltip.org

OPEN ACCESS This is an open access article under the CC BY-NC license (http://creativecommons.org/licenses/by-nc/4.0/). 
C hronic obstructive pulmonary disease (COPD) is characterized by chronic, progressive inflammation of the airways that leads to serious lung damage and mortality. [1] Systemic and pulmonary hypoxia, inflammation, and oxidative stress are the basis of the systemic complications of COPD. ${ }^{[2,3]}$ Comorbidities such as cardiovascular disease, musculoskeletal abnormalities, diabetes, osteoporosis, autoimmune abnormalities, depression, and obstructive sleep apnea are commonly seen in COPD patients. ${ }^{[4]}$

The retina and retinal microvascular structures are unique in that they allow the effects of many systemic diseases to be monitored in vivo. Changes in these tissues can be assessed quantitatively and qualitatively using different imaging methods. Optical coherence tomography angiography (OCTA) is a new technique that provides detailed images of blood flow and the retinal-choroidal capillary network. OCTA enables quick and non-invasive diagnosis of retinal vascular pathologies. The previous studies using optical coherence tomography (OCT) have shown changes in choroidal structure and the retinal nerve fiber layer due to COPD. ${ }^{[5,6]}$ The few published studies using OCTA revealed decreased peripapillary and parafoveal vascular density in patients with sleep apnea, which, like COPD, may cause end organ damage due to hypoxia and oxidative stress. ${ }^{[7,8]}$

To the best of our knowledge, no studies in which OCTA imaging was used to show the effects of COPD on the retinal capillary network have been published. The purpose of this study was to investigate changes in microcirculation in the retinal vascular plexus and choriocapillaris of patients with COPD using OCTA.

\section{Methods}

\section{Participants and Data Collection}

This prospective, cross-sectional study adhered to the tenets of the Declaration of Helsinki and received approval from the ethics committee of a tertiary training and research hospital (2063/07.08.2018). Informed consent was obtained from all individual participants included in the study. Patients with COPD followed between August 2018 and May 2019 in the Department of Thoracic Diseases were included in the study. According to Global Intelligence for Chronic Obstructive Lung Disease criteria, patients with a forced expiratory volume in the first second (FEV1)/forced vital capacity (FVC) ratio of $<70 \%$ and FEV1 values below $80 \%$ were included in the study. ${ }^{[9]}$ The FEV1/FVC ratios were then evaluated using spirometric tests. Patients undergoing steroid therapy; using mechanical ventilator therapy; or suffering from diabetes mellitus, hypercholesteremia, hypertension, or concomitant cardiac pathologies were excluded from the study. The patients were then referred to the Department of Ophthalmology for detailed ophthalmologic examination, including measurement of refractive errors, determination of best corrected visual acuity (BCVA) using a Snellen chart, measurement of intraocular pressure (IOP) using the Goldmann applanation tonometer, and slitlamp biomicroscopy and dilated fundus examinations.

Inclusion criteria for all participants were as follows: a BCVA of $20 / 20$, IOP values within $12-20 \mathrm{mmHg}$, axial lengths (AL) within 20-25 mm, an open angle on the gonioscopy examination, and cup-to-disc ratios $\leq 0.3$. After sitting and resting for $15 \mathrm{~min}$, blood pressure and oxygen saturation were measured using a fingertip pulse oximeter. Smoking was not allowed for one hour before the tests. The body mass indices (BMIs) of all patients were calculated. Patients with additional anterior or posterior segment pathology such as age-related macular degeneration, cataract that could cause decreased visual acuity, history of ocular surgery or trauma, glaucoma, uveitis, optic neuritis, keratoconus, amblyopia, strabismus, and spherical equivalent $> \pm 3 \mathrm{D}$ were excluded from the study.

Healthy controls of similar age and gender were evaluated in this study. Non-smoking volunteers who were admitted to the ophthalmology outpatient clinic with a BCVA of at least 20/20, no additional systemic or ocular pathology, and oxygen saturation measurements from pulse oximetry above $97 \%$ formed the control group. The right eyes of all participants were included in the study and OCTA imaging was performed in $3 \mathrm{~mm} \times 3 \mathrm{~mm}$ macular mode.

\section{OCTA Imaging Protocol}

A blinded experienced technician performed OCTA data collection and processing on all participants. OCTA images were obtained using the AngioVue (Version 2017.1, Optovue, Inc., Fremont, CA, USA). AngioVue uses a split-spectrum amplitude decorrelation to detect vascular density and flow and to capture the OCTA images. This system has an A scan repetition rate of $70 \mathrm{kHz}$, wavelength of $840 \mathrm{~nm}$, and depth resolution of $5 \mu \mathrm{m}$ in tissue. Before imaging, each subject's pupils were dilated with a combination of $0.5 \%$ tropicamide and $2.5 \%$ phenylephrine. Study participants underwent OCTA imaging following a protocol that included AngioVue OCT 3D volumes of $3 \mathrm{~mm} \times 3 \mathrm{~mm}$ macula with activation of the eye-tracking system. The device produced 2 OCT units, each consisting of $304 \times 304$ A-scans with 2 B-scans captured in $3 \mathrm{~s}$. The inner retinal lamina was defined as the layers between the internal limiting membrane and the outer plexiform layer (OPL). Volumes of the outer retina between the Bruch membrane and the inner nuclear layer/OPL junction were automatically segmented by the AngioVue software. Other processes were executed using the embedded software (Version 
2017.1). Previously published articles describe the algorithm in detail. ${ }^{[10-12]}$ Vascular density was defined as the percentage of the area occupied by the large vessels and microvasculature. Foveal zone vessel density was defined as the area of the small circle, with a diameter of $1 \mathrm{~mm}$, and the parafoveal zone vessel density was defined as the area of the middle circle, with a diameter of $3 \mathrm{~mm}$. In addition, the zones were automatically divided into four equal quadrants (temporal, nasal, inferior, and superior) and two equal hemispheres (superior and inferior) (Fig. 1). Foveal avascular zone (FAZ) area in whole retina and FAZ perimeter (PERIM) were automatically obtained through the FAZ assessment tool, which measures the vascular density within a $300 \mu \mathrm{m}$ distance of the FAZ area determined by the device ${ }^{[13]}$ and also the flow index, which is the key parameter of perfusion, was automatically calculated using the AngioVue software (Fig. 2). Low-quality scans were ex- cluded and repeated until the signal strength index was $\geq 70$. OCTA images with artifacts (such as motion artifacts or blinking artifacts) that could affect the analysis were also excluded from the study. Because the OCTA device used in this study did not contain a normative database, right eyes of healthy subjects were included in the study as a control group.

\section{Statistical Analysis}

Statistical Package for the Social Sciences (SPSS), Version 22.0 for Windows (SPSS Inc., Chicago, IL) was used for statistical analysis. Descriptive statistics are presented as mean plus or minus standard deviation for numerical variables. Pearson's Chi-square test and the one-sample Chi-square test were performed to analyze the categorical variables. For the comparisons between the COPD group and the control group, an independent sample t-test was performed for normally distributed data, and a

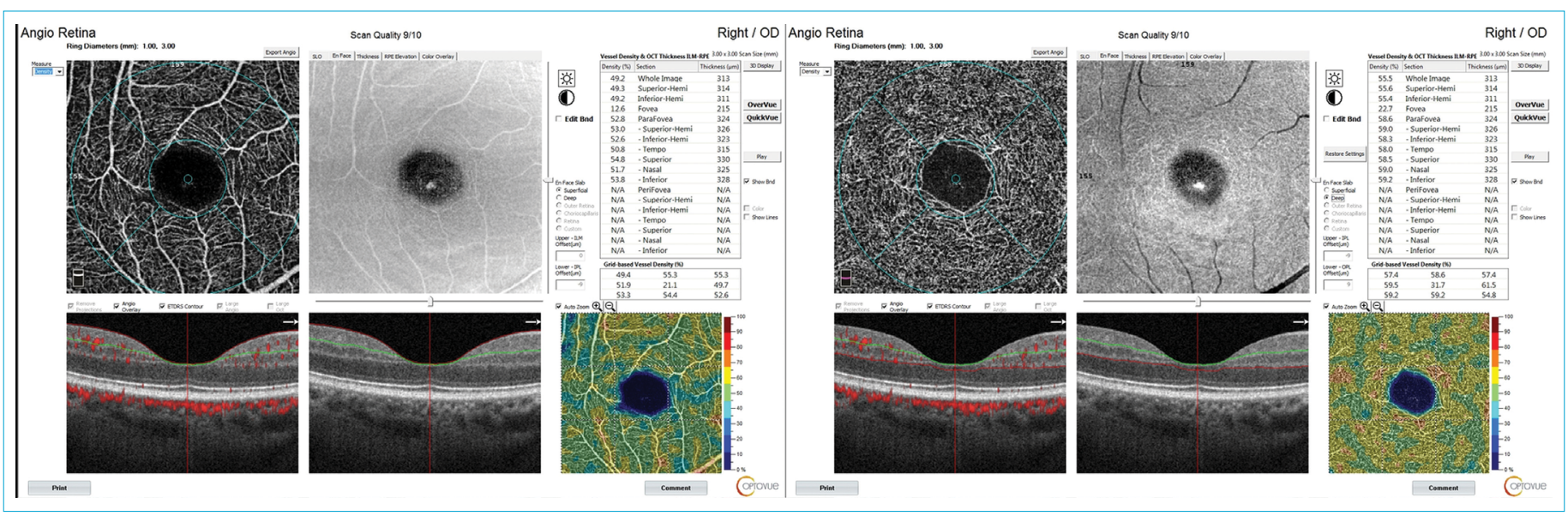

Figure 1. Density assessment tool of optical coherence tomography angiography. Superficial (a) and deep (b) capillary plexuses demonstrated. The zones that were automatically divided by the analytic software of the device are shown at the right corner of each figure.

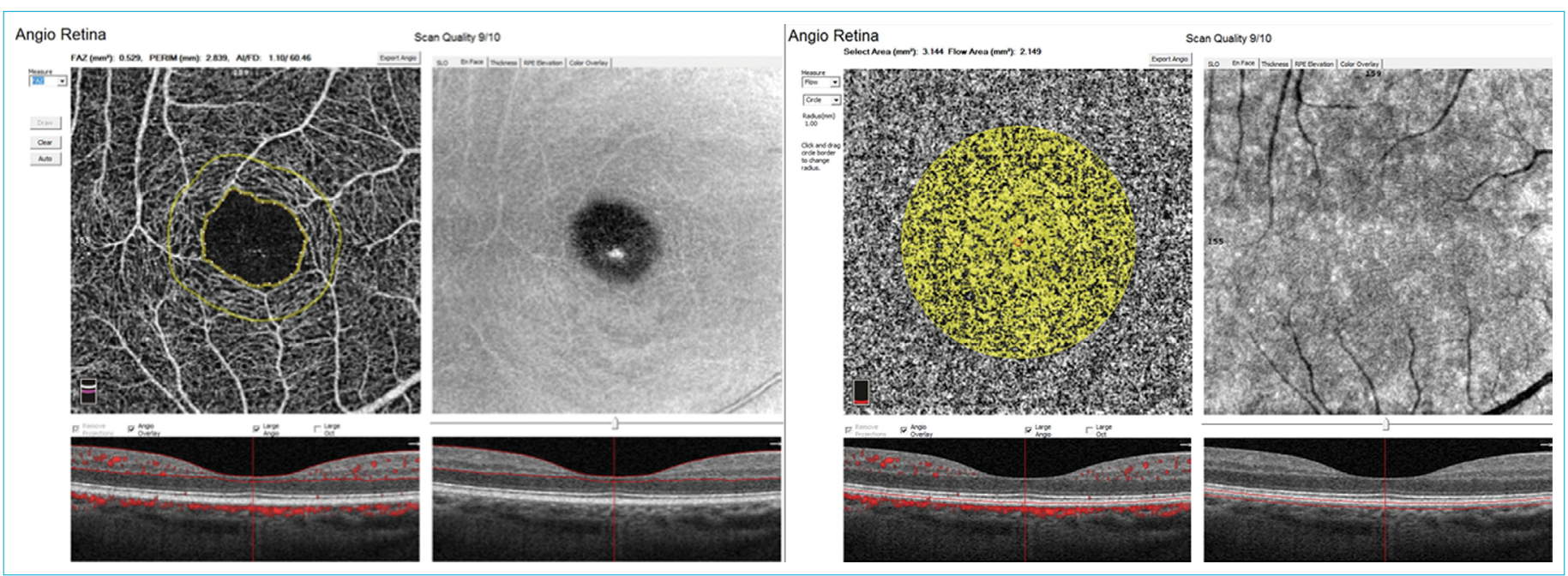

Figure 2. FAZ (a) and Flow (b) assessment tools of optical coherence tomography angiography. FAZ area $\left(\mathrm{mm}^{2}\right)$ in whole retina, FAZ perimeter $(\mathrm{mm})$ and Choriocapillaris Flow area $\left(\mathrm{mm}^{2}\right)$ are demonstrated. 
Kruskal-Wallis (Mann-Whitney $U$ ) test was performed for non-normally distributed data. The statistical significance level was $p<0.05$.

\section{Results}

Fifty-three patients were referred from the Department of Thoracic Diseases to the ophthalmology clinic. Twenty-three patients were excluded due to comorbide diseases or poor image quality (seven with cataract, four with age-related macular degeneration, three with high refractive error, and nine with poor image quality). The right eyes of 30 patients ( 21 males and nine females) and the right eyes of 30 healthy controls ( 21 males and nine females) were included in the study. There were no statistically significant differences between the groups in terms of age, systolic and diastolic systemic blood pressure measurements, BMI, AL, and IOP values. The mean FEV1/FVC ratio of the COPD group was $61.5 \pm 6.4 \%$ and the mean FEV1 score of the COPD group was $42.9 \pm 15.7 \%$, consistent with the moderate-to-severe COPD. Table 1 shows the demographic and clinical characteristics of the participants.

As shown in Table 2, no statistically significant differences were observed in the outer retinal flow area and choriocapillary flow area measurements between the groups $(p=0.609$ and $p=0.162$, respectively). There was no significant difference in FAZ and PERIM values between the groups ( $p=0.725$ and $p=0.820$, respectively).

Table 3 presents the comparison of vascular density measurements between the groups. There were no statistically significant differences between the groups in all investigated superficial foveal and parafoveal areas ( $p>0.05$, for all). There was also no statistically significant difference between the groups in the deep foveal area. When the deep parafoveal area was examined separately, vascular density measurements in the COPD group were statistically significantly lower than in the control group in all investigated areas except the superior and inferior parafoveal quadrants.

\section{Discussion}

In the current study, we analyzed alterations in the retinal capillary network in patients with COPD. We found a statistically significant decrease in deep capillary plexus (DCP) density in all investigated parafoveal areas except the superior and inferior quadrants. Although we did not find statistically significant differences in blood flow between the groups, the previous studies have shown that ocular blood flow decreases as a result of increased vascular resistance and decreased blood flow due to chronic hypoxia and hypercapnia in patients with COPD. In a study using Doppler
Table 1. Clinical and demographic characteristics of the COPD and control groups

\begin{tabular}{lcccc}
\hline & COPD group & & Control group & p \\
\cline { 2 - 2 } \cline { 5 - 5 } & Avg \pm SD & & Avg \pm SD & \\
\hline Age (year) & $59.9 \pm 7.1$ & & $57.8 \pm 6.6$ & $0.164^{*}$ \\
Systolic BP (mmHg) & $116.0 \pm 9.3$ & & $116.0 \pm 6.7$ & $1.000^{*}$ \\
Diastolic BP (mmHg) & $76.0 \pm 10.4$ & & $75.0 \pm 8.2$ & $0.575^{*}$ \\
FEV1 & $42.9 \pm 15.7$ & & \\
FEV1/FVC & $61.5 \pm 6.4$ & & \\
Smoking pack year & $36.5 \pm 7.4$ & & \\
Disease duration (year) & $10.5 \pm 4.2$ & & \\
AL (mm) & $22.6 \pm 0.9$ & & $22.1 \pm 1.0$ & $0.074^{*}$ \\
IOP (mmHg) & $15.1 \pm 2.2$ & & $14.8 \pm 2.1$ & $0.586^{*}$ \\
\hline
\end{tabular}

*Kruskal-Wallis (Mann-Whitney U-test). $\mathrm{sO}_{2}$ : Oxygen saturation; $\mathrm{BP}$ : Blood pressure; FEV1: Forced expiratory volume in first second; FVC: Forced vital capacity; AL: Axial length; IOP: Intraocular pressure; Avg: Average; SD: Standard deviation; COPD: Chronic obstructive pulmonary disease.

Table 2. FAZ, PERIM measurements, and retinal and choroidal flow area in both groups

\begin{tabular}{|c|c|c|c|}
\hline & \multirow{2}{*}{$\frac{\text { COPD group }}{\text { Avg. } \pm S D}$} & \multirow{2}{*}{$\frac{\text { Control group }}{\text { Avg. } \pm \text { SD }}$} & \multirow[t]{2}{*}{$\mathbf{p}$} \\
\hline & & & \\
\hline $\mathrm{FAZ}\left(\mathrm{mm}^{2}\right)$ & $0.22 \pm 0.06$ & $0.23 \pm 0.08$ & $0.725^{*}$ \\
\hline PERIM $\left(\mathrm{mm}^{2}\right)$ & $1.901 \pm 0.28$ & $1.912 \pm 0.29$ & $0.820^{*}$ \\
\hline Outer retina flow area & $0.31 \pm 0.10$ & $0.34 \pm 0.13$ & $0.609^{*}$ \\
\hline Choriocapillaris flow area & $2.013 \pm 1.05$ & $1.973 \pm 1.15$ & $0.162^{*}$ \\
\hline
\end{tabular}

*Kruskal-Wallis (Mann-Whitney U-test). FAZ: Foveal avascular zone; PERIM: FAZ perimeter; Avg: Average; SD: Standard deviation; COPD: Chronic obstructive pulmonary disease.

ultrasound (DUS), hemodynamic changes in extraocular orbital arteries have been shown in patients with COPD. ${ }^{[14]}$ Moreover, choroidal tissue thinning has been shown in the previous studies as a result of changes in choroidal blood flow in patients with COPD. ${ }^{[15]}$ Whether microvascular blood flow changes due to chronic hypoxia in COPD patients remains unclear.

The retinal and choroidal vascular networks are complex vascular systems that can be involved in many systemic disorders. Numerous factors contribute to the regulation of retinal and choroidal blood flows. Retinal blood flow, oxygenation, and arterial tonus in retinal layers are maintained by autoregulation through secretion of many mediators, including nitric oxide (NO) and endothelin in retinal endothelial and non-endothelial cells, while choroidal blood flow is primarily under control of the autonomic nervous system and hormones. ${ }^{[16-18]}$

Chronic hypoxia and hypercapnia may affect retinal and choroidal blood flow. In patients with COPD, changes such as atheromatous plaques, thrombotic lesions in both pul- 
Table 3. Superficial and deep vascular plexus density (\%) in both groups

\begin{tabular}{|c|c|c|c|}
\hline & COPD group & Control group & $\mathbf{p}$ \\
\hline Sp. Parafoveal density & $49.8 \pm 3.2$ & $49.8 \pm 3.7$ & $0.976^{*}$ \\
\hline Sp. Parafoveal superior hemi density & $49.5 \pm 3.4$ & $49.4 \pm 3.6$ & $0.904^{*}$ \\
\hline Sp. Parafoveal inferior hemi density & $50.2 \pm 3.2$ & $50.2 \pm 3.8$ & $0.974^{*}$ \\
\hline Sp. Parafoveal superior density & $50.8 \pm 3.5$ & $50.8 \pm 4.4$ & $0.992^{*}$ \\
\hline Sp. Parafoveal nasal density & $49.5 \pm 3.2$ & $49.2 \pm 3.8$ & $0.694^{*}$ \\
\hline Sp. Parafoveal inferior density & $50.9 \pm 3.5$ & $51.1 \pm 4.3$ & $0.885^{*}$ \\
\hline D. Fovea density & $36.5 \pm 4.8$ & $36.2 \pm 4.2$ & $0.592^{*}$ \\
\hline D. Parafoveal density & $52.7 \pm 4.1$ & $54.9 \pm 2.6$ & $0.034^{*}$ \\
\hline D. Parafoveal nasal density & $52.7 \pm 3.7$ & $55.3 \pm 2.9$ & $0.004^{*}$ \\
\hline D. Parafoveal inferior density & $52.5 \pm 4.7$ & $54.7 \pm 3.0$ & $0.128^{*}$ \\
\hline
\end{tabular}

*Kruskal-Wallis (Mann-Whitney U-test). Sp.: Superficial; D.: Deep; Avg: Average; SD: Standard deviation; COPD: Chronic obstructive pulmonary disease.

monary, and peripheral vessels. ${ }^{[19-21]}$ The previous studies have also shown that oxidative stress, inflammation, endothelial dysfunction, increased coagulability, polycythemia, and atherosclerosis may develop in retinal inner layers due to chronic hypoxia. ${ }^{[22,23]}$ Recently, Palkovits et al. ${ }^{[24]}$ reported hypoxia of retinal vessels in patients with severe COPD and found that peripheral arterial oxygen saturation was well correlated with retinal arterial oxygen saturation. The previous studies have also shown that systemic endothelin-1 levels are elevated in patients with COPD, and increased levels of endothelin-1 have been shown to affect retinal vessels. ${ }^{[25,26]}$ It is well known that decreased NO and increased endothelin-1 synthesis due to endothelial dysfunction causes vasoconstriction. ${ }^{[27]}$

Responses to the changes may vary due to differences in the location and structure of the two plexuses. The superficial capillary plexus (SCP) is primarily located within the ganglion cell layer, while the DCP is primarily located within the inner nuclear layer, with the two plexuses interconnected through vertically positioned vessels. ${ }^{[28]} \mathrm{How}-$ ever, perfusion pressure may be higher in the SCP due to the branches of the SCP leaving the retinal artery before the branches of the DCP. ${ }^{[29]}$ In addition, the DCP is chiefly formed by venous collecting channels; thus, the DCP may be more sensitive to venous pressure increases and low oxygen saturation than the SCP. ${ }^{[30]}$ However, it is not clear whether these changes are the result of vasoconstriction, direct vascular damage, or capillary loss after direct cellular damage to the inner nuclear layer.
It has been shown that the DCP is particularly sensitive to systemic or ophthalmic diseases affecting the retina. Consistent with our study, researchers have demonstrated a decrease in DCP density in patients receiving hydroxychloroquine treatment and in diabetic cases without retinopathy on OCTA. ${ }^{[31,32] ~ I n ~ a ~ s t u d y ~ i n ~ p a t i e n t s ~ w i t h ~ r h e g m a t o g e n o u s ~}$ retinal detachment, the authors proposed that the DCP may be particularly vulnerable to tissue hypoxia and increased inflammatory cytokine levels. ${ }^{[29]}$ Data supporting these results were also obtained in Behçet uveitis. ${ }^{[33]}$ The previous reports investigating patients with retinal vein occlusion have shown that the decrease in vascular perfusion was more remarkable in the DCP than in the SCP. ${ }^{[30,34]}$ Similarly, we found that parafoveal vessel densities in the DCP were significantly decreased in the COPD group compared to the control group, while no significant difference was found in the total parafoveal vessel density of the SCP. Two possible reasons for this decrease are the loss of vascular structure and vasoconstriction as a result of chronic hypoxia and endothelial dysfunction. It is also possible that the metabolic activities of bipolar, Müller, amacrine, and horizontal cells in the inner nuclear layer may be more sensitive to hypoxia. OCT and OCTA are insufficient to demonstrate the etiology of the decrease in the vascular capillary network.

OCTA studies on sleep apnea have revealed changes in retinal vascular density as a result of hypoxia, with a mechanism similar to that observed in COPD. In one of these studies, Moyal et al. ${ }^{[35]}$ stated that there was not any significant difference between the patient and healthy groups 
in vascular density in the parafoveal and peripapillary areas. However, in another study on obstructive sleep apnea syndrome, Wang et al. ${ }^{[7]}$ showed a significant decrease in vascular density in the parafoveal and peripapillary areas in patients with sleep apnea syndrome. Although these studies focused on different clinical entities, our research also support the theory that ischemia may cause decreased vascular density in the parafoveal area.

Smoking is a major cause of endothelial dysfunction and microvascular changes throughout the body. ${ }^{[36]}$ Grzybowski and Holder ${ }^{[37]}$ observed reduced blood flow at the optic nerve in their DUS study, leading them to conclude that nicotine stimulates the sympathetic nervous system and causes vasoconstriction. In contrast, we did not observe any statistically significant differences in retinal blood flow between the two groups, despite the fact that all patients in the COPD group in this study were chronic smokers. Heavy smoking in the patient group might be another reason for the decreased parafoveal vascular density.

Several limitations of this study should be emphasized. None of our patients was consistent with the mild stage COPD. As a result we cannot extend our findings to patients with mild COPD. We were also limited in the number of cases with images of acceptable quality and patients with comorbid diseases.

\section{Conclusion}

To the best of our knowledge, this is the first study to investigate foveal and parafoveal vessel density in patients with COPD. Our results suggested that retinal vascular density seems to be affected by COPD-related hypoxemia and endothelial dysfunction. We believe that our study yields clinically important results that may serve as the basis for further studies in this field.

\section{Disclosures}

Ethics Committee Approval: The research protocol was approved by the Local Ethics Committee of Şişli Hamidiye Etfal Training and Research Hospital (Date: 07.08.2018, Decision Number: 2063).

Peer-review: Externally peer-reviewed.

Conflict of Interest: None declared.

Financial Disclosure: The authors declare that this study received no financial support.

Authorship Contributions: Concept - A.A.A., E.D., M.K., E.O.Z., M.A.O., G.D.A., M.E.K., D.G.; Design - A.A.A., E.D., M.K., M.A.O., E.O.Z., G.D.A., M.E.K., D.G.; Supervision - A.A.A., E.D., M.K., M.A.O., E.O.Z., G.D.A., M.E.K., D.G.; Fundings - A.A.A., E.D., M.K., M.A.O., E.O.Z., G.D.A., M.E.K., D.G.; Materials - A.A.A., E.O., M.K., M.A.O., E.O.Z., G.D.A., M.E.K., D.G.; Data collection \&/or processing - A.A.A., E.O., M.K., M.A.O., E.O.Z., G.D.A., M.E.K., D.G.; Analysis and/or inter- pretation - A.A.A., E.O., M.K., M.A.O., E.O.Z., G.D.A., M.E.K., D.G.; Literature search - A.A.A., E.O., M.K., M.A.O., E.O.Z., G.D.A., M.E.K., D.G.; Writing - A.A.A., E.O., M.K., M.A.O., E.O.Z., G.D.A., M.E.K., D.G.; Critical review - A.A.A., E.O., M.K., M.A.O., E.O.Z., G.D.A., M.E.K., D.G.

\section{References}

1. Rodriguez-Roisin R, Rabe KF, Vestbo J, Vogelmeier C, Agustí A; all previous and current members of the Science Committee and the Board of Directors of GOLD (goldcopd.org/committees/). Global Initiative for Chronic Obstructive Lung Disease (GOLD) $20^{\text {th }}$ Anniversary: a brief history of time. Eur Respir J 2017;50:1700671.

2. Gan WQ, Man SF, Senthilselvan A, Sin DD. Association between chronic obstructive pulmonary disease and systemic inflammation: a systematic review and a meta-analysis. Thorax 2004;59:574-80. [CrossRef]

3. Choudhury G, Rabinovich R, MacNee W. Comorbidities and systemic effects of chronic obstructive pulmonary disease. Clin Chest Med 2014;35:101-30. [CrossRef]

4. Agusti A, Soriano JB. COPD as a systemic disease. COPD 2008;5:133-8. [CrossRef]

5. Gok M, Ozer MA, Ozen S, Botan Yildirim B. The evaluation of retinal and choroidal structural changes by optical coherence tomography in patients with chronic obstructive pulmonary disease. Curr Eye Res 2018;43:116-21. [CrossRef]

6. Ugurlu E, Pekel G, Altinisik G, Bozkurt K, Can I, Evyapan F. New aspect for systemic effects of COPD: eye findings. Clin Respir J 2018;12:247-52. [CrossRef]

7. Wang XY, Li M, Ding X, Han DM. Application of optical coherence tomography angiography in evaluation of retinal microvascular changes in patients with obstructive sleep apnea syndrome. [Article in Chinese]. Zhonghua Yi Xue Za Zhi 2017;97:2501-5.

8. Yu J, Xiao K, Huang J, Sun X, Jiang C. Reduced retinal vessel density in obstructive sleep apnea syndrome patients: an optical coherence tomography angiography study. Invest Ophthalmol Vis Sci 2017;58:3506-12. [CrossRef]

9. Osthoff M, Jenkins C, Leuppi J. Chronic obstructive pulmonary disease--a treatable disease. Swiss Med Wkly 2013;143:w13777.

10. Spaide RF, Klancnik JM Jr, Cooney MJ. Retinal vascular layers imaged by fluorescein angiography and optical coherence tomography angiography. JAMA Ophthalmol 2015;133:45-50. [CrossRef]

11. Jia Y, Bailey ST, Hwang TS, McClintic SM, Gao SS, Pennesi ME, et al. Quantitative optical coherence tomography angiography of vascular abnormalities in the living human eye. Proc Natl Acad Sci U S A 2015;112:E2395-402. [CrossRef]

12. Jia Y, Tan O, Tokayer J, Potsaid B, Wang Y, Liu JJ, et al. Split-spectrum amplitude-decorrelation angiography with optical coherence tomography. Opt Express 2012;20:4710-25. [CrossRef]

13. Mo S, Krawitz B, Efstathiadis E, Geyman L, Weitz R, Chui TY, et al. Imaging foveal microvasculature: optical coherence tomography angiography versus adaptive optics scanning light ophthalmoscope fluorescein angiography. Invest Ophthalmol Vis Sci 
2016;57:OCT130-40. [CrossRef]

14. Ozer T, Altin R, Ugurbas SH, Ozer Y, Mahmutyazicioglu K, Kart L. Color Doppler evaluation of the ocular arterial flow changes in chronic obstructive pulmonary disease. Eur J Radiol 2006;57:63-8. [CrossRef]

15. Ozcimen M, Sakarya Y, Kurtipek E, Bekci TT, Goktas S, Sakarya R, et al. Peripapillary choroidal thickness in patients with chronic obstructive pulmonary disease. Cutan Ocul Toxicol 2016;35:26-30.

16. Pournaras CJ, Rungger-Brändle E, Riva CE, Hardarson SH, Stefansson E. Regulation of retinal blood flow in health and disease. Prog Retin Eye Res 2008;27:284-330. [CrossRef]

17. Schmetterer L, Findl O, Strenn K, Jilma B, Graselli U, Eichler HG, et al. Effects of endothelin-1 (ET-1) on ocular hemodynamics. Curr Eye Res 1997;16:687-92. [CrossRef]

18. Kur J, Newman EA, Chan-Ling T. Cellular and physiological mechanisms underlying blood flow regulation in the retina and choroid in health and disease. Prog Retin Eye Res 2012;31:377-406.

19. Minoguchi K, Yokoe T, Tazaki T, Minoguchi H, Tanaka A, Oda N, et al. Increased carotid intima-media thickness and serum inflammatory markers in obstructive sleep apnea. Am J Respir Crit Care Med 2005;172:625-30. [CrossRef]

20. Kwon YS, Chi SY, Shin HJ, Kim EY, Yoon BK, Ban HJ, et al. Plasma C-reactive protein and endothelin-1 level in patients with chronic obstructive pulmonary disease and pulmonary hypertension. J Korean Med Sci 2010;25:1487-91. [CrossRef]

21. Cazzola M, Matera MG, Rogliani P, Page C. Treating systemic effects of COPD. Trends Pharmacol Sci 2007;28:544-50. [CrossRef]

22. Yun $\mathrm{CH}$, Jung $\mathrm{KH}$, Chu K, Kim SH, Ji KH, Park HK, et al. Increased circulating endothelial microparticles and carotid atherosclerosis in obstructive sleep apnea. J Clin Neurol 2010;6:89-98. [CrossRef]

23. Khayat R, Patt B, Hayes D Jr. Obstructive sleep apnea: the new cardiovascular disease. Part I: Obstructive sleep apnea and the pathogenesis of vascular disease. Heart Fail Rev 2009;14:143-53.

24. Palkovits S, Lasta M, Boltz A, Schmidl D, Kaya S, Hammer M, et al. Measurement of retinal oxygen saturation in patients with chronic obstructive pulmonary disease. Invest Ophthalmol Vis Sci 2013;54:1008-13. [CrossRef]

25. Polak K, Luksch A, Frank B, Jandrasits K, Polska E, Schmetterer L. Regulation of human retinal blood flow by endothelin-1. Exp Eye Res 2003;76:633-40. [CrossRef]

26. Roland M, Bhowmik A, Sapsford RJ, Seemungal TA, Jeffries DJ, Warner TD, et al. Sputum and plasma endothelin-1 levels in exacerbations of chronic obstructive pulmonary disease. Thorax 2001;56:30-5. [CrossRef]

27. Priou P, Gagnadoux F, Tesse A, Mastronardi ML, Agouni A, Mesli- er $\mathrm{N}$, et al. Endothelial dysfunction and circulating microparticles from patients with obstructive sleep apnea. Am J Pathol 2010;177:974-83. [CrossRef]

28. Snodderly DM, Weinhaus RS, Choi JC. Neural-vascular relationships in central retina of macaque monkeys (Macaca fascicularis). J Neurosci 1992;12:1169-93. [CrossRef]

29. Woo JM, Yoon YS, Woo JE, Min JK. Foveal avascular zone area changes analyzed using oct angiography after successful rhegmatogenous retinal detachment repair. Curr Eye Res 2018;43:6748. [CrossRef]

30. Adhi M, Filho MA, Louzada RN, Kuehlewein L, de Carlo TE, Baumal $\mathrm{CR}$, et al. Retinal capillary network and foveal avascular zone in eyes with vein occlusion and fellow eyes analyzed with optical coherence tomography angiography. Invest Ophthalmol Vis Sci 2016;57:OCT486-94. [CrossRef]

31. Ozek D, Onen M, Karaca EE, Omma A, Kemer OE, Coskun C. The optical coherence tomography angiography findings of rheumatoid arthritis patients taking hydroxychloroquine. Eur J Ophthalmol 2019;29:532-7. [CrossRef]

32. Carnevali A, Sacconi R, Corbelli E, Tomasso L, Querques L, Zerbini $G$, et al. Optical coherence tomography angiography analysis of retinal vascular plexuses and choriocapillaris in patients with type 1 diabetes without diabetic retinopathy. Acta Diabetol 2017;54:695-702. [CrossRef]

33. Khairallah M, Abroug N, Khochtali S, Mahmoud A, Jelliti B, Coscas $\mathrm{G}$, et al. Optical coherence tomography angiography in patients with Behçet uveitis. Retina 2017;37:1678-91. [CrossRef]

34. Coscas F, Glacet-Bernard A, Miere A, Caillaux V, Uzzan J, Lupidi M, Coscas G, Souied EH. Optical Coherence Tomography Angiography in Retinal Vein Occlusion: Evaluation of Superficial and Deep Capillary Plexa. Am J Ophthalmol. 2016 Jan;161:160-71.e1-2.

35. Moyal L, Blumen-Ohana E, Blumen M, Blatrix C, Chabolle F, Nordmann JP. Parafoveal and optic disc vessel density in patients with obstructive sleep apnea syndrome: an optical coherence tomography angiography study. Graefes Arch Clin Exp Ophthalmol 2018;256:1235-43. [CrossRef]

36. Michaud SE, Dussault S, Groleau J, Haddad P, Rivard A. Cigarette smoke exposure impairs VEGF-induced endothelial cell migration: role of $\mathrm{NO}$ and reactive oxygen species. J Mol Cell Cardiol 2006;41:275-84. [CrossRef]

37. Grzybowski A, Holder GE. Tobacco optic neuropathy (TON) - the historical and present concept of the disease. Acta Ophthalmol 2011;89:495-9. [CrossRef] 